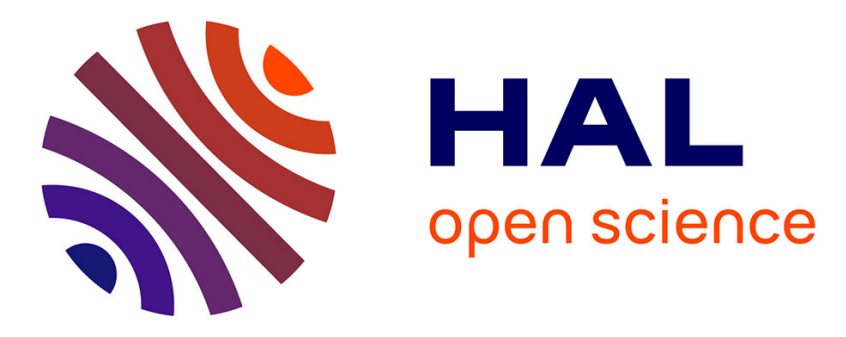

\title{
Hydrophobic chemical surface functionalization of hydroxyapatite nanoparticles for naphthalene removal
}

K. Bouiahya, A. Oulguidoum, A. Laghzizil, M. Shalabi, J.M. M Nunzi, Sylvie Masse

\section{- To cite this version:}

K. Bouiahya, A. Oulguidoum, A. Laghzizil, M. Shalabi, J.M. M Nunzi, et al.. Hydrophobic chemical surface functionalization of hydroxyapatite nanoparticles for naphthalene removal. Colloids and Surfaces A: Physicochemical and Engineering Aspects, 2020, 595, pp.124706. 10.1016/j.colsurfa.2020.124706 . hal-03348487

\section{HAL Id: hal-03348487 \\ https: / hal.sorbonne-universite.fr/hal-03348487}

Submitted on 19 Sep 2021

HAL is a multi-disciplinary open access archive for the deposit and dissemination of scientific research documents, whether they are published or not. The documents may come from teaching and research institutions in France or abroad, or from public or private research centers.
L'archive ouverte pluridisciplinaire $\mathbf{H A L}$, est destinée au dépôt et à la diffusion de documents scientifiques de niveau recherche, publiés ou non, émanant des établissements d'enseignement et de recherche français ou étrangers, des laboratoires publics ou privés. 


\title{
Hydrophobic chemical surface functionalization of hydroxyapatite nanoparticles for naphthalene removal
}

\author{
K. Bouiahya ${ }^{\mathrm{a}}$, A. Oulguidoum ${ }^{\mathrm{a}}$, A. Laghzizil $^{\mathrm{a}, *}$, M. Shalabi $^{\mathrm{b}}$, J.M. Nunzi $^{\mathrm{b}}$, Sylvie MASSE ${ }^{\mathrm{c}}$ \\ ${ }^{\text {a }}$ Laboratory of Applied Chemistry of Materials, Mohammed V University in Rabat, Faculty of Science, Rabat BP. 1014 Agdal, Morocco \\ ${ }^{\mathrm{b}}$ Department of Chemistry, Queen's University, Kingston, ON K7L-3N6, Canada \\ ${ }^{\mathrm{c}}$ Sorbonne Université, CNRS, Laboratoire de Chimie de la Matière Condensée de Paris, LCMCP, F-75005 Paris, France
}

GRAPHICAL ABSTAACT

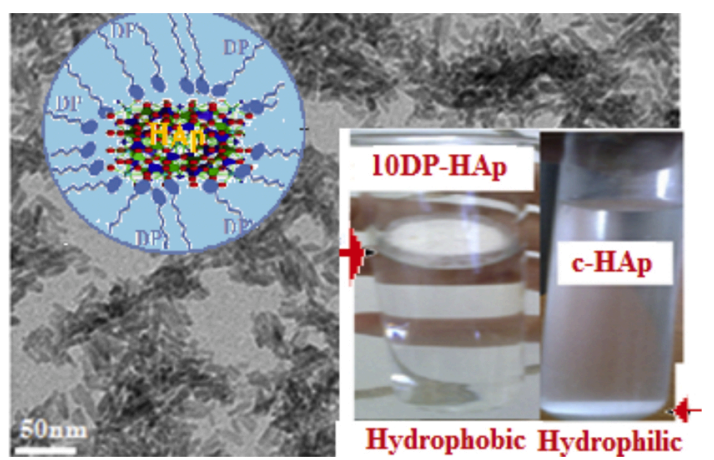

\author{
A R T I C L E I N F O \\ Keywords: \\ Hydrophilic/hydrophobic surface \\ Hybrid hydroxyapatite \\ Nanoparticles \\ Adsorption
}

\begin{abstract}
A B S T R A C T
Hydrophobic apatite monolith nanoparticles were prepared by grafting of dodecylphosphate (DP) onto hydroxyapatite. A modification in the synthesis was used to develop a hydrophobic surface in order to improve the dispersion and compatibility of organoapatite particles for the sensing and separation of hydrophobic substances. Results indicate that DP grafting onto the apatite is quantitative. Structural analyses of the as-received materials show that the grafting approach did not significantly alter the apatite microstructure, but modifies the hydrophobic character and surface properties of the hybrid material. Conversion of the hydrophilic surface of hydroxyapatite to hydrophobic was carried out to better retain naphthalene as a polynuclear aromatic hydrocarbon model.
\end{abstract}

\footnotetext{
* Corresponding author.

E-mail address: laghzizi@fsr.ac.ma (A. Laghzizil).
}

\section{Introduction}

The physico-chemical properties of materials depend essentially on their specific surface and their chemical composition [1-3]. To improve these properties, the modification of their surface makes it possible to control and promote the active sites resulting in a good adsorption. Surface modification by adhesion or in-situ grafting of organic molecules was considered effective [3]. Among the criteria for an effective 
surface are: an important surface charge, an hydrophilic/hydrophobic character of the modified surface, the potential to trap toxic substances. In particular, polycyclic aromatic hydrocarbons (PAHs) that are released to the aquatic environment as by-products of the incomplete combustion of some organic substances are chemically persistent and non-biodegradable [4,5]. Naphthalene is generally considered as a model compound for the examination of the environmental and health aspects of polynuclear aromatic hydrocarbons [6,7]. It has a tar odor and sublimates at room temperature by emitting vapors, which are highly toxic and long persistent environmental pollutants. Thus, it is useful to develop effective treatment processes that will help urban and rural areas getting rid of these toxic substances $[8,9]$. Adsorption processes are widely used in the purification of wastewaters [7-9]. The development of surface-controlled materials was thought as a solution to retain these hydrophobic molecules. Activated carbon is the most generally used sorbent with some restrictions such as sensitivity of regeneration to high temperature and thermal and chemical instability as well as costly reactivation and limited design flexibility $[10,11]$. Hydrophobic porous materials such as functionalized zeolites [12,13], silica [14,15], modified bentonite [16] have been used for the adsorptive removal of naphthalene from aqueous solutions. Surface modifications have been applied to hydroxyapatite materials in order to tune their physico-chemical properties [17-20]. Moreover, the presence of amphoteric and hydrogenous sites enables reaction with organic modifiers to form hybrid apatites [21-23]. However, the nature of the organic moieties can change the hydrophobicity of the solid surface as well as its structural and physical properties [24-26]. Among them, dodecylphosphate, with its particularly long aliphatic carbon chain, can affect the initially hydrophilic hydroxyapatite and form a hydrophobic water-fearing surface. This paper explores the affinity of hydrophobic mesoporous apatite surfaces with hydrophobic toxic organic compounds contained into water. In this study, the hydrophilic surface of hydroxyapatite was converted to hydrophobic to better uptake higher naphthalene concentrations from the aquatic environment. The adsorptive removal of naphthalene from the hydrophobic apatite from aqueous solutions was further evaluated by kinetic models (e.g., pseudo-first-order and pseudo-second-order equations) and two isotherms (e.g., Langmuir, Freundlich).

\section{Materials and methods}

\subsection{Preparation}

The converted hydroxyapatite (c-HAp) was prepared as previously described by a dissolution/reprecipitation method from a natural phosphate ore collected from the Bengurir region (Morocco) $[27,28]$. After dissolving the natural phosphate using concentrated $\mathrm{HNO}_{3}$ acid ( $65 \mathrm{vol} \%$ ), the filtrated solution containing calcium and phosphate ions was precipitated by addition of a concentrated ammonia solution (25\%) until $\mathrm{pH} \approx 10$. The final white suspensions were aged for $24 \mathrm{~h}$ at room temperature, filtered, washed and dried at $100{ }^{\circ} \mathrm{C}$. For hydrid apatite, the dodecylphosphate (DP, $\mathrm{C}_{12} \mathrm{H}_{27} \mathrm{O}_{4} \mathrm{P}$ ) was added to $200 \mathrm{~mL}$ of the calcium and phosphate-containing solution originating from ore dissolution and a concentrated ammonia solution was added up to $\mathrm{pH}=10$ under vigorous stirring at room temperature. The xerogel was maintained in contact with the reaction solution for $6 \mathrm{~h}$ at $25^{\circ} \mathrm{C}$ under stirring. It was then filtered and repeatedly washed with distilled water and finally dried for $24 \mathrm{~h}$ in an oven at $100{ }^{\circ} \mathrm{C}$. The percent of organophosphorus functionnalized by DP was calculated as $\%=100 . P_{\mathrm{org}} /\left(P_{i^{-}}\right.$ norg $\left.+P_{\text {org }}\right)$. In varying the proportion of DP, several hybrid samples, named wDP-HAp, were prepared using DP molar ratios of 0, 2.5, 5, 7.5, 10 and $15 \mathrm{wt} \%$.

\subsection{Analytical measurements}

The crystalline phases were identified by powder X-ray diffractometry (X' PERT PRO MPD) with CuKo radiation. FTIR spectra were recorded in the 4000 to $400 \mathrm{~cm}^{-1}$ spectral region on a Bruker IFS66V FTIR. Specific surface areas were determined by multi-point $\mathrm{N}_{2}$ gas sorption at $77 \mathrm{~K}$ using a Micromeritics ASAP 2010 instrument according to the Brunauer-Emmett-Teller (BET) method using adsorption data in the 0.05 to 0.25 relative pressure range. Pore size distribution was determined using the Barret-Joyner-Halenda (BJH) approximation in the mesoporous range. Total carbon content of the samples was determined using a CHNOS analyzer "Flash EA112 THERMO". Calcium and phosphorus analyses were performed by inductively coupled plasma atomic emission spectroscopy (ICP-Ultima 2). Transmission electron microscope TEM images were taken with a TecnaiG ${ }^{2}$ apparatus.

\subsection{Adsorption experiments and modelling}

Naphthalene $\left(\mathrm{C}_{10} \mathrm{H}_{8}\right.$, molecular weight $\left.128.16 \mathrm{~g} / \mathrm{mol}\right)$ is a hydrophobic compound with low solubility in water of $30 \mathrm{mg} \mathrm{L}^{-1}$, but high solubility in most organic solvents. Sorption experiments were performed in a batch reactor equipped with a multi-stirrer. Kinetics of the naphthalene sorption on different hydrophobic powders dried at $100{ }^{\circ} \mathrm{C}$ and hydrophilic pure HAp were studied using a $20 \mathrm{mg} \mathrm{L}^{-1}$ naphthalene solution in contact with $200 \mathrm{mg}$ of powder at pH 5.6 and room temperature. The mixture was filtered and the residual naphthalene in the filtrate was monitored using a UV-vis spectrophotometer working at the strong absorption band of $220 \mathrm{~nm}$. The adsorbed amount of naphthalene on wDP-HAp powders at time $\mathrm{t}\left(\mathrm{q}_{\mathrm{t}}\right.$ in $\mathrm{mg} \mathrm{g}^{-1}$ ) was calculated as follows: $\mathrm{q}_{\mathrm{t}}=\left(\mathrm{C}_{0}-\mathrm{C}_{\mathrm{t}}\right) . \mathrm{V} / \mathrm{m}$, where $\mathrm{C}_{0}$ and $\mathrm{C}_{\mathrm{t}}$ are the phenol concentrations (in $\mathrm{mg}$ $\mathrm{L}^{-1}$ ) in the liquid phase initially and at any time t, respectively, " $\mathrm{m}$ " is the mass ( $\mathrm{g}$ ) of the adsorbent in the solution, and $\mathrm{V}$ is the solution volume (L). To determine the kinetics parameters of the sorption reactions, Lagergren pseudo-first [29] and pseudo-second order [30] models have been applied to experimental data. The first model, expressed as: log $\left(\mathrm{q}_{\mathrm{e}}-\mathrm{q}_{\mathrm{t}}\right)=\log \mathrm{q}_{\mathrm{e}, 1}-\mathrm{k}_{1} . \mathrm{t} / 2.303$, allows the determination of $\mathrm{q}_{\mathrm{e}, 1}$ the adsorbed amount of naphthene at equilibrium $\left(\mathrm{mgg}^{-1}\right)$ and $\mathrm{k}_{1}$ the first order kinetic constant $\left(\mathrm{min}^{-1}\right)$. The pseudo-second model described by $\mathrm{t} / \mathrm{q}_{\mathrm{t}}=1 /\left(\mathrm{k}^{2} \mathrm{q}_{\mathrm{e}, 2}^{2}\right)+\mathrm{t} / \mathrm{q}_{\mathrm{e}, 2}$ provides the calculated amount of adsorbed naphthene at equilibrium $\mathrm{q}_{\mathrm{e}, 2}\left(\mathrm{mg} \mathrm{g}^{-1}\right)$ and $\mathrm{k}_{2}$ the second order kinetic constant (g. $\mathrm{mg}^{-1} \mathrm{~min}^{-1}$ ).

The sorption isotherms were obtained after $3 \mathrm{~h}$ of contact at pH 5.6 by mixing $0.2 \mathrm{~g}$ of adsorbent with $100 \mathrm{ml}$ of naphthalene solutions ranging from 5 to $100 \mathrm{mg} \mathrm{L}^{-1}$. The highly concentrated solutions of naphthalene, up $30 \mathrm{mg} \mathrm{L}^{-1}$, were prepared by adding a certain volume of methanol and subsequently diluted by distilled water of $1 \% \mathrm{v}: \mathrm{v}$ in order to increase its solubility. This approach reflects the wastewater/ industrial effluent complexity, which contains many chemical entities such as alcohols that do not adsorb on many adsorbents and so does not compete for adsorption on apatite from the water-methanol solution containing naphthalene. Sorption isotherms were analyzed using the Langmuir [31] and Freundlich models [32]. The first model, $\mathrm{C}_{\mathrm{e}} / \mathrm{q}_{\mathrm{e}}=$ $\left.\left(1 / \beta . q_{L}\right)+C_{e} / q_{L}\right)$, allows the calculation of the maximum amount of adsorbed naphthalene at equilibrium $\mathrm{q}_{\mathrm{L}}\left(\mathrm{mgg}^{-1}\right)$, and $\beta$ the Langmuir constant $\left(\mathrm{L} \mathrm{mg}^{-1}\right)$ related to the adsorption energy. The second model, $\log q_{e}=\log K_{f}+(1 / n) \log C_{e}$, leads to the determination of $K_{f}$ the Freundlich constant correlated to the maximum adsorption capacity and $\mathrm{n}$ the adsorption intensity.

\section{Results and discussion}

\subsection{Structural and textural properties}

As Fig. 1 shows, the interaction of DP with $\mathrm{Ca}^{2+}$ ions occurs through interplay between organic and inorganic phosphate in calcium coordination, forming a unique and poorly crystalline apatite phase in the DPconcentration range. The high structural disorder induced by DP grafting is responsible for the observed diminution of crystallinity, which strongly depends on the DP content as well as the thermal stability of the 
compounds. At high DP content, heat treatment at $800{ }^{\circ} \mathrm{C}$ induces a partial conversion of DP-HAp nanocrystals into $\beta$-tricalcium phosphate $(\beta$-TCP).

Infrared spectra of the DP-HAp materials display the vibration modes of $\mathrm{PO}_{4}$ groups, which are characteristic of the apatite structure (Fig. 2). The small shift of $\mathrm{PO}_{4}$ bands to higher frequencies with DP content rising is related to the structural disorder and the nature of the $\mathrm{P}-\mathrm{O}$ bond. However, the $\mathrm{P}-\mathrm{O}$ bands coming from the organic phosphorus in $\mathrm{DP}$ molecules overlap those of the inorganic phosphorus in the apatite lattice. FT-IR spectra of the grafted DP-HAp materials exhibit weak peaks originating from organic carbon in the $1420-1450 \mathrm{~cm}^{-1}$ range, contrary to the pure c-HAp, which is constitutive of carbonated apatite. This reflects the replacement of $\mathrm{CO}_{3}^{2-}$ ions originally in the phosphate rock by organophosphorus groups in the grafted materials. After surface grafting, new vibration bands are detected at 2000, 2300 and $2900 \mathrm{~cm}^{-1}$, belonging to the aliphatic $\mathrm{C}-\mathrm{H}$ stretch of DP in the apatite lattice.

TG analysis shows two major mass losses according to the grafting of DP in wDP-HAp powders (Fig. 3). First, a very slight evaporation of water (1-2\%) at $120^{\circ} \mathrm{C}$ demonstrating the hydrobibicity of the surface of the samples, then the combustion of organic fractions (5-18\%) between 120 and $600{ }^{\circ} \mathrm{C}$ and finally a slight loss observed at more than 600 ${ }^{\circ} \mathrm{C}$, attributable to the elimination of resistant organic matter and /or the crystallization process.

Powders were chemically analyzed, as reported in Table 1 . With unvarying calcium and phosphorus in starting NP precursor, the addition of DP molecules affects the $\mathrm{Ca} / \mathrm{P}$ molar ratio of the precipitates. For 15DP-HAp sample, the $\mathrm{Ca} / \mathrm{P}$ value is close to 1.5 , characteristic of the presence of $\beta-\mathrm{Ca}_{3}\left(\mathrm{PO}_{4}\right)_{2}$ detected by XRD when the product is heattreated at $800{ }^{\circ} \mathrm{C}$. Thermogravimetric analysis was performed (Table 1). In the temperature range between 200 and $600{ }^{\circ} \mathrm{C}$. There is evidently a greater weight loss for hybrid apatites attributed to the decomposition of the organic material in the apatite powders. It can be seen that the weight loss of the products increases with the grafted DP content, confirming the chemical analysis performed. TEM images of the dried hybrid powders are shown in Fig. 4; exhibiting well-defined nanoparticles of similar morphologies that look like stick particles with different lengths varying from $10-40 \mathrm{~nm}$. After heating at $800{ }^{\circ} \mathrm{C}$, spherical aggregates of fused nanoparticles with various morphologies are observed, corresponding to pure hydroxyapatite as demonstrated by IR data.

Fig. 5a shows the $\mathrm{N}_{2}$-adsorption/desorption isotherms for all wDPHAp hydrophobic materials characterized by type IV isotherms according to the IUPAC classification. The presence of adsorption/ desorption hysteresis is largely linked to the texture of the mesoporous material (distribution of the pore size, geometry of the pores and the connectivity). Similar results were obtained by other researchers [22,23, 28].

Using the BET model, specific surface areas $\left(\mathrm{S}_{\mathrm{BET}}\right)$ are presented in Table 1 . After drying at $100{ }^{\circ} \mathrm{C}$, surface modification induced by the DP introduction increased the $\mathrm{S}_{\mathrm{BET}}$ of apatite remarkably at the lowest DP content $(2.5 \%)$, but increasing more the DP content resulted in a gradual reduction of surface area until $110 \mathrm{~m}^{2} \mathrm{~g}^{-1}$ for 10DP-HAp. This is related to the high molecular disorder introduced by the organic molecules into the apatite structure; it is therefore possible that the organic moieties be located into the pores or blocks their entrance. However, hybrid material nanocomposites exhibit close $\mathrm{S}_{\mathrm{BET}}$ values in the $110-150 \mathrm{~m}^{2} \mathrm{~g}^{-1}$ range that is significantly higher than that of the converted hydroxyapatite c-HAp $\left(100 \mathrm{~m}^{2} \mathrm{~g}^{-1}\right)$ and to $20 \mathrm{~m}^{2} \mathrm{~g}^{-1}$ for NP. This strongly suggests that both types of particles are more evenly dispersed within the powder. Pore size distributions (Fig. 5b) indicated that the diameter of pores in the functionalized apatite were between 8 and $11 \mathrm{~nm}$, including mesopores slightly larger for c-HAp $(12.8 \mathrm{~nm})$.

Fig. 6 shows the significant improvement of the unmodified c-HAp sample behavior compared to that of the modified 10DP-HAp sample, indicating that the dodecylphosphate addition has a deep influence in increasing the hydrophobicity of the synthesized apatite nanoparticles. Initially, hydroxyapatite is hydrophilic due to the presence of the $\mathrm{OH}$ groups on the surface of the particles that form hydrogen bonds and subsequently decant under their weight. Upon introducing the DP molecules, the 10DP-HAp powder floats on the water, showing the role played by DP grafting for the production of hydroxyapatite with a hydrophobic surface.

To our knowledge, this is the first time that such hydrophobic apatite surfaces were manufactured. Two approaches have been explored. The 
first one relies on the formation of hydroxyapatite in the presence of DP that exhibits affinity for the calcium of the mineral phase and the second relates to obtaining hydrophobic surfaces capable of retaining hydrophobic pollutants such as naphthalene. As a result, the carbon chain of the DP graft makes the surface of the hydrophobic apatite floating in the water and able to retain hydrophobic organic species such as hydrocarbons and oils.

\subsection{Adsorption behaviors}

Based on extensive characterization, the influence of DP on the structure and surface chemistry of the materials was discussed in relation to their naphthalene sorption behavior. The fixation of naphthalene on hydrophobic wDP-HAp samples was carried out under statistical conditions. We limited the present approach to the effect of contact time, $\mathrm{pH}$, and initial concentration on naphthalene removal from water. Fig. 7 shows the evolution of the amount adsorbed as a function of time. In modifying the nature of the hydrophobicity of the material surface, the kinetic behavior is characterized by a strong fixation of naphthalene on the solid in the first minutes, followed by a slow process until equilibrium. For an initial concentration of $20 \mathrm{ppm}$ of naphthene, the maximum amounts adsorbed on the hybrid apatites are given in Table 2. At equilibrium, the hybrid wDP-HAp apatites bind more naphthalene than cHAp and the retention of naphthalene improves markedly with the DP graft content of the c-HAp structure. This improvement is due to the nature of the interactions between the novel hydrophobic surfaces created by grafting long carbon-based DP functions.

To analyze these results in more details, two models were evaluated for fitting the experimental data. In most cases, the first-order model led to low $\mathrm{R}^{2}$ values whereas values larger than 0.999 were obtained with the second-order model (Table 2). The amount of naphthalene sorption at equilibrium varies from ca. $3.11 \mathrm{mg} \mathrm{g}^{-1}$ on hydrophilic HAp to ca. 7.7 $\mathrm{mg} \mathrm{g}^{-1}$ on the hydrophobic 10DP-HAp surface. It seems that the specific surface of the adsorbent is not the only parameter to be taken into account during the adsorption process, but that the chemical composition of the surface is the determining parameter affecting the elimination of naphthalene.

Sorption isotherms as a function of the equilibrium naphthalene concentration were obtained after $3 \mathrm{~h}$ as contact time at pH 5.6 (Fig. 8). The hydrophobic 10DP-HAp sample shows high experimental naphthalene adsorption performance compared to the hydrophilic cHAp.

In order to model the experimental data, the use of the Langmuir model was unsuccessful because it did not reproduce the low concentration range, whereas fitting by Freundlich equation is apparently correct $\left(\mathrm{R}^{2}>0.99\right)$ (Table 3). These sorption capacities can be related to (i) the accessible hydrophobic apatite surface, (ii) the molecular packing on the surface and (iii) the nature of the naphthalene-apatite interaction.

In order to optimize the $\mathrm{pH}$ for maximum elimination efficiency, experiments were conducted in a pH range from 3 to 11 (Fig. 9). The $\mathrm{pH}$ variation had little effect on the adsorption process. Results showed that naphthalene was better removed at $\mathrm{pH} 6$ and 5 by c-HAp and wDP-HAp ( $w=2.5$ and 10 ) respectively, while the adsorptive removal decreased on both sides of these $\mathrm{pH}$ values. The good adsorption obtained at $\mathrm{pH} 6$ below the neutral $\mathrm{pH}$ of naphthalene is linked to the surface of the grafted apatites containing $\mathrm{Ca}^{2+}$ and $\mathrm{PO}_{4}^{3-}$ ions, which may be responsible for this $\mathrm{pH}$ change. These results are in good agreement with those reported elsewhere [33], in which it was shown that the maximum floatability of apatite was reached at $\mathrm{pH}$ around 6 .

Since the naphthalene, molecules are non-polar and can interact with the hydrophobic wDP-HAp surface by their polyaromatic structure, involving dispersive interactions with the $\pi$-electron-rich carbons. The strong $\pi-\pi$ interaction between the naphthalene molecules and hydrophobic surface is responsible for the adsorption. In addition, the hydrophilic character of the pure the hydroxyapatite has caused strong competition of water adsorption due to its high polarity. This competition reduced the accessibility of naphthalene molecules within the pores of the HAp surface. In opposition, the use of hydrophobic surfaces prevents access of water molecules to the solid surface and promotes naphthalene adsorption. This is consistent with the forces responsible for naphthalene adsorption that are stronger in more hydrophobic materials.

\section{Conclusions}

New hydrophobic surface apatite nanoparticles were synthesized by grafting dodecylphosphate. The introduction of aliphatic carbon chains in the apatite structure is of great interest to elaborate modified hydrophobic apatite nanoparticles that are promising for the removal of hydrophobic pollutants from water. Kinetic studies showed that the adsorption process was extremely fast in all employed sorbents. Experimental results show that 10DP-HAp has good performances and can be successfully used for the removal of naphthalene from aqueous solutions. The simple kinetic model of the pseudo second-order equation was successfully applied to predict the adsorption of naphthalene on the hydrophobic grafted apatite while Freundlich model can be used to describe the adsorption equilibrium. The use of naphthalene as a model molecule allows us to better study the adsorption process of polycyclic pollutants on apatite-based materials and to determine the best pa-rameters that can influence retention. Experimental trials open up a promising new path to reach water treatment with inexpensive and abundant hybrid materials such as functionalized apatites.

\section{Author contribution}

The manuscript was written through the contributions of all authors that they have approved the final version of the manuscript.

K. Bouiahya: Conceptualization, Methodology, and characterization.

A. Oulguidoum, characterization and Writing- Original draft preparation.

M. Shalabi: Visualization Data processing.

A. Laghzizil:, Supervision, Validation.

J-M Nunzi: Reviewing and Editing.

\section{Declaration of Competing Interest}

There is no conflict of interest between all authors and no known competing financial interests or personal relationships that could have appeared to influence the work reported in this paper.

\section{References}

[1] L. Li, S.Q. Liu, J.X. Liu, Surface modification of coconut shell based activated carbon for the improvement of hydrophobic VOC removal, J. Hazard. Mater. 192 (2011) 683-690. 
[2] F. Al-Ali, A. Lebugle, I. Rico-Lattes, G. Etemad-Moghadam, Preparation and characterization of new hybrid organic/inorganic systems derived from calcium ( $\alpha$-aminoalkyl)-phosphonates and -phosphonocarboxylates, J. Colloid Interface Sci. 289 (2005) 504-511.

[3] L. El Hammari, A. Laghzizil, A. Saoiabi, P. Barboux, M. Meyer, Chemical modification of porous calcium hydroxyapatite surfaces by grafting phenylphosphonic and phenylphosphite acids, Colloid Surf. 289 (2006) 84-88.

[4] S.W. Karickhoff, K.R. Morris, Sorption dynamics of hydrophobic pollutants in sediment suspensions, Environ. Toxicol. Chem. 4 (4) (1985) 469-479.

[5] D.M. Wassenberg, R.T. Di Giulio, Synergistic embryo toxicity of polycyclic aromatic hydrocarbon aryl hydrocarbon receptor agonists with cytochrome P4501 A inhibitors in fundulus heteroclitus, Environ. Health Perspect. 17 (2004) 16581664.

[6] M. Zander, in: A. Bjrseth (Ed.), Handbook of Polycyclic Aromatic Hydrocarbons, Dekker, New York, 1983, pp. 1-26.

[7] X. Ge, F. Tian, Z. Wu, Y. Yan, G. Cravotto, Z. Wu, Adsorption of naphthalene from aqueous solution on coal-based activated carbon modified by microwave induction: microwave power effect, Chem. Eng. Process. Process. Intensif. 91 (2015) 67-77.

[8] A.R. Yaqubzadeh, A. Ahmadpour, T. Rohani Bastami, M.R. Hataminia, Low-cost preparation of silica aerogel for optimized adsorptive removal of naphthalene from aqueous solution with central composite design (CCD), J. Non. Solids 447 (2016) 307-314.

[9] S.M. Yakout, A.A.M. Daifullah, S.A. El-Reefy, Adsorption of naphthalene phenanthrene and pyrene from aqueous solution using low-cost activated carbon derived from agricultural wastes, Adsorpt. Sci. Technol. 31 (2013) 293-301.

[10] S.E. Moradi, Naphthalene removal from water by novel mesoporous carbon nitride adsorbent, Chem. Biochem. Eng. Q 27 (2013) 365-372.

[11] E.A. Müller, K.E. Gubbins, Molecular simulation study of hydrophilic and hydrophobic behavior of activated carbon surfaces, Carbon 36 (1998) 1433-1438.

[12] C.O. Ania, B. Cabal, J.B. Parra, J.J. Pis, Importance of hydrophobic character of activated carbons on the removal of naphthalene from aqueous phase, Adsorpt. Sci. Technol. 25 (2007) 155-168.

[13] M. Seredych, A. Gierak, Influence of water on adsorption of organic compounds from its aqueous solutions on surface of synthetic active carbons, Colloids Surf. A 245 (2004) 61-67.

[14] F. Ahnert, H.A. Arafat, N.E. Pinto, A study of the influence of hydrophobicity of activated carbon on the adsorption equilibrium of aromatics in non-aqueous media, Adsorption 9 (2003) 311-319.

[15] F.C. Chiung, Y.C. Ching, H.C. Ken, T.T. Wen, L.S. Je, H.C. Yi, Adsorption of naphthalene on zeolite from aqueous solution, J. Colloid Interface Sci. 277 (2004) 29-34.

[16] C. Wang, S. Leng, Y. Xu, Q. Tian, X. Zhang, L. Cao, J. Huang, Preparation of amino functionalized hydrophobic zeolite and its adsorption properties for chromate and naphthalene, Minerals 8 (2018) 145-158.
[17] D. Wang, E. McLaughlin, R. Pfeffer, Y.S. Lin, Adsorption of oils from pure liquid and oil-water emulsion on hydrophobic silica aerogels, Sep. Purif. Technol. 99 (2012) 28-35.

[18] S. Standeker, Z. Novak, Z. Knez, Adsorption of toxic organic compounds from water with hydrophobic silica aerogels, J. Colloid Interface Sci. 310 (2007) 362-368.

[19] E.M.O. Kaya, A.S. Ozcan, O. Gok, A. Ozcan, Adsorption kinetics and isotherm parameters of naphthalene onto natural- and chemically modified bentonite from aqueous solutions, Adsorption 19 (2013) 879-888.

[20] H.W. Choi, H.J. Lee, K.J. Kim, H.M. Kim, S.C. Lee, Surface modification of hydroxyapatite nanocrystals by grafting polymers containing phosphonic acid groups, J. Colloid Interface Sci. 304 (2006) 277-281.

[21] H. Tanaka, A.Y. asukawa, K. Kandori, T. Ishikawa, Surface modification of calcium hydroxyapatite with hexyl and decyl phosphates, Colloids Surf. A 125 (1997) 53-62.

[22] L. El Hammari, H. Marroun, A. Laghzizil, A. Saoiabi, C. Roux, J. Livage, T. Coradin, Organically modified porous hydroxyapatites: a comparison between alkylphosphonate grafting and citrate chelation, J. Solid State Chem. 181 (2008) 848-854.

[23] S. Saoiabi, S. El Asri, A. Laghzizil, T. Coradin, K. Lahlil, Nanoporous surface of organofunctionalized hydroxyapatite fabricated from natural phosphate rock, Mater. Lett. 64 (2010) 2679-2681.

[24] W.A. Ducker, D. Mastropietro, Forces between extended hydrophobic solids: is there a long-range hydrophobic force? Curr. Opin. Colloid Interface Sci. 22 (2016) 51-58.

[25] L. Karlina, Cl. Azmiyawati, A. Darmawan, Synthesis and characterization of hydrophobic silica prepared by different acid catalysts, in: IOP Conference Series Materials Science and Engineering, 509, 2019, 012065.

[26] J. Liu, Z.A. Janjua, M. Roe, F. Xu, B. Turnbull, K.-S. Choi, X. Hou, Superhydrophobic/icephobic coatings based on silica nanoparticles modified by selfassembled monolayer, 2016, Nanomaterials 6 (12) (2016) 232-241.

[27] S. El Asri, A. Laghzizil, A. Alaoui, A. Saoiabi, R. M'Hamdi, K.E.L. Abbassi, A. Hakam, Structure and thermal behaviors of Moroccan phosphate rock (Bengurir), J. Therm. Anal. Calorim. 95 (2009) 11-19.

[28] S. El Asri, A. Laghzizil, A. Saoiabi, A. Alaoui, K. Al Abassi, R. M’hamdi, T. Coradin, A. Saoiabi, A novel process for the fabrication of nanoporous apatites from Moroccan phosphate rock, Colloids Surf. A 350 (2009) 73-78.

[29] S. Lagergren, Zur theorie der sogenannten adsorption geloster stoffe, Kungliga Svenska Vetenskapsakademiens, Handlingar 24 (1898) 1-39.

[30] Y.S. Ho, G. McKay, Pseudo-second order model for sorption processes, Process. Biochem. 34 (1999) 451-465.

[31] I. Langmuir, The adsoprtion of gases on plane surfaces of glass, mica and platinum, J. Am. Chem. Soc. 40 (1918) 1361-1403.

[32] H.M.F. Freundlich, Over the adsorption in solution, J. Phys. Chem. 57 (1906) $385-471$.

[33] J. Pires, N.L. Pinto, A. Carvalho, M.B. Carvalho, Assessment of hydrophobichydrophilic properties of microporous materials from water adsorption isotherms, Adsorption 9 (2003) 303-309.
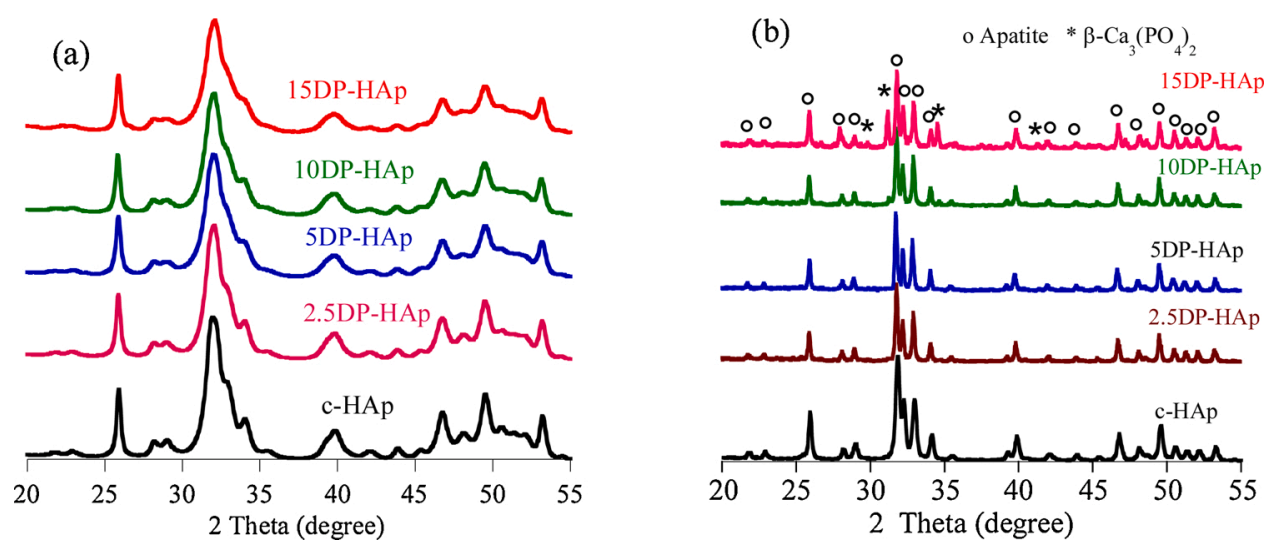

Fig. 1. XRD patterns of wDP-HAp powders (a) dried at $100{ }^{\circ} \mathrm{C}$ and (b) calcined at $800{ }^{\circ} \mathrm{C}$. 

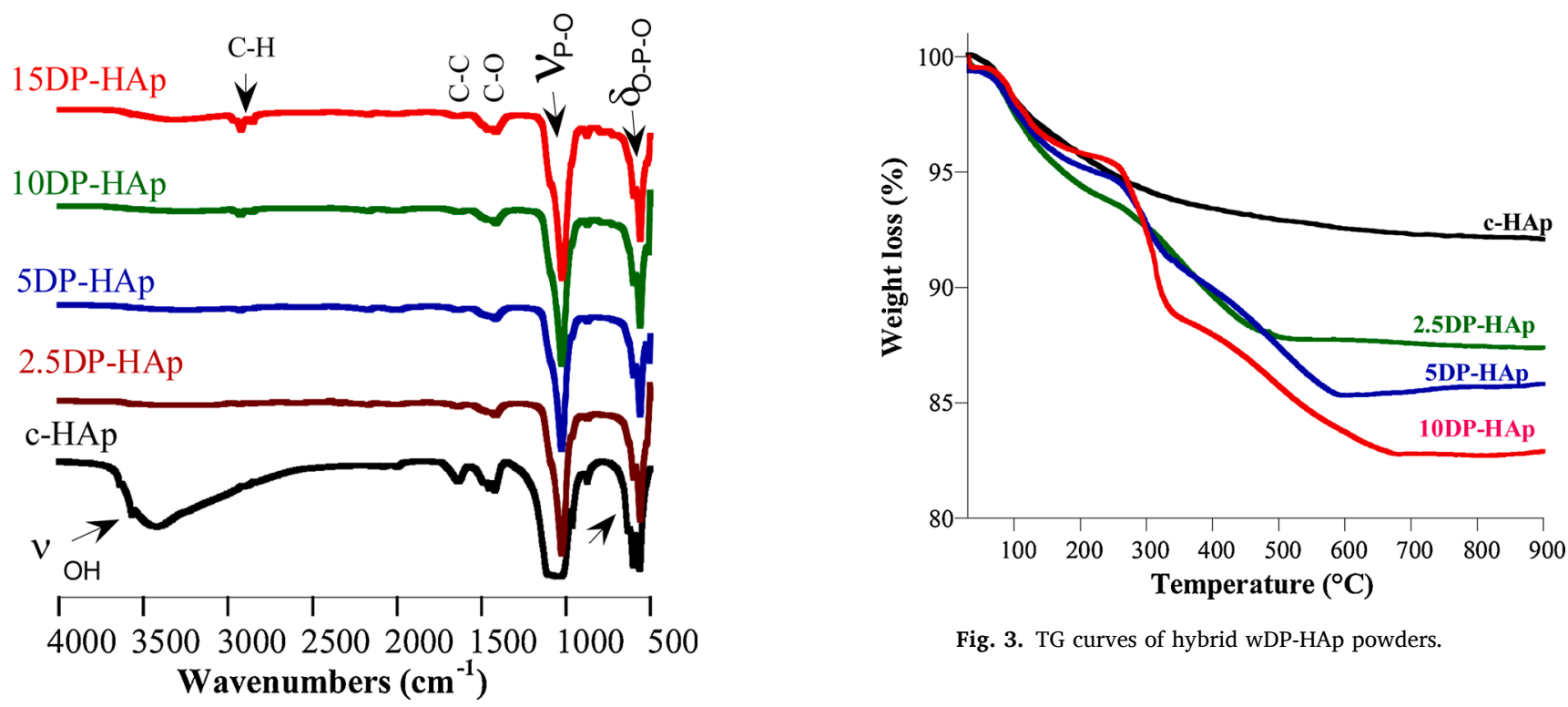

Fig. 3. TG curves of hybrid wDP-HAp powders.

Fig. 2. IR spectra of wDP-HAp powders.
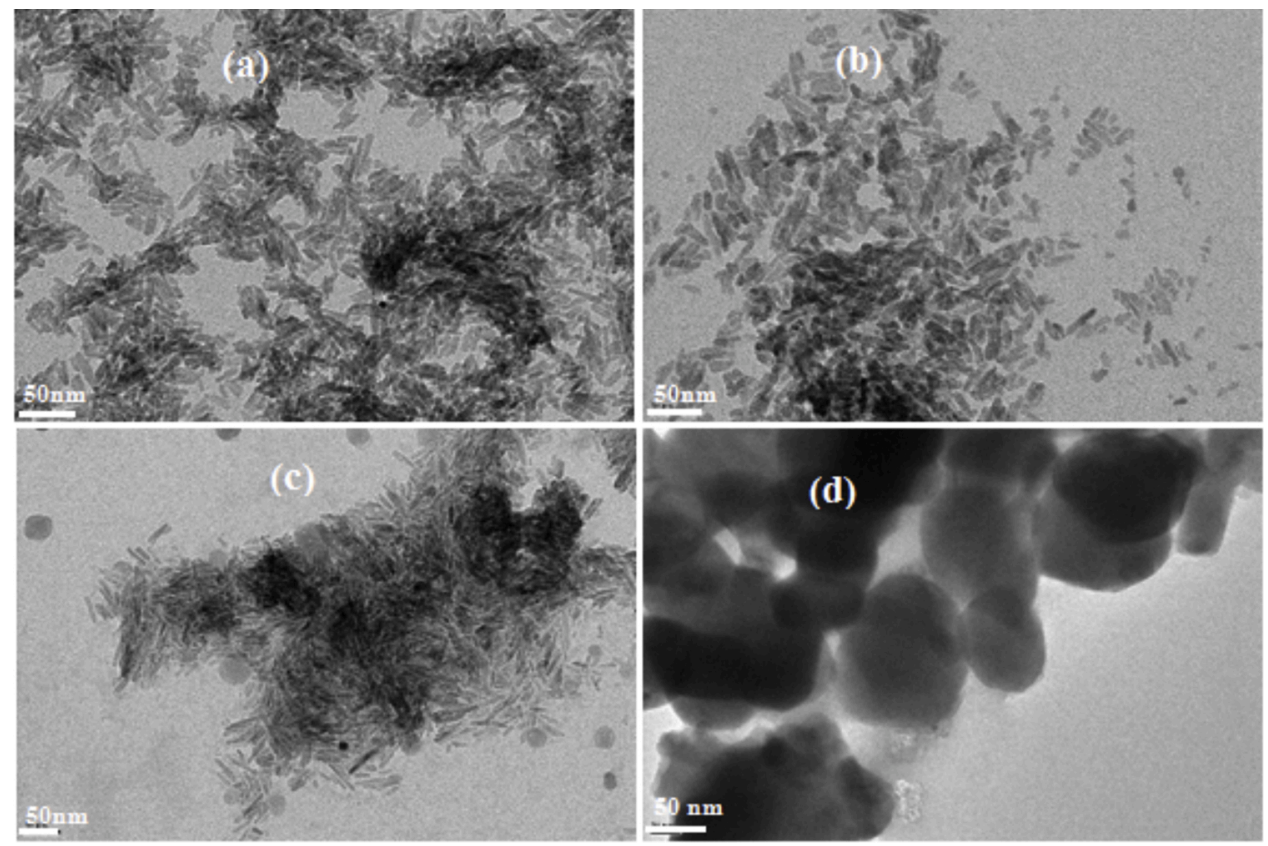

Fig. 4. TEM images of $10 \mathrm{DP}-\mathrm{HAp}$ powders: (a, b and c) dried at $100{ }^{\circ} \mathrm{C}$ and (d) calcined at $800{ }^{\circ} \mathrm{C}$. 


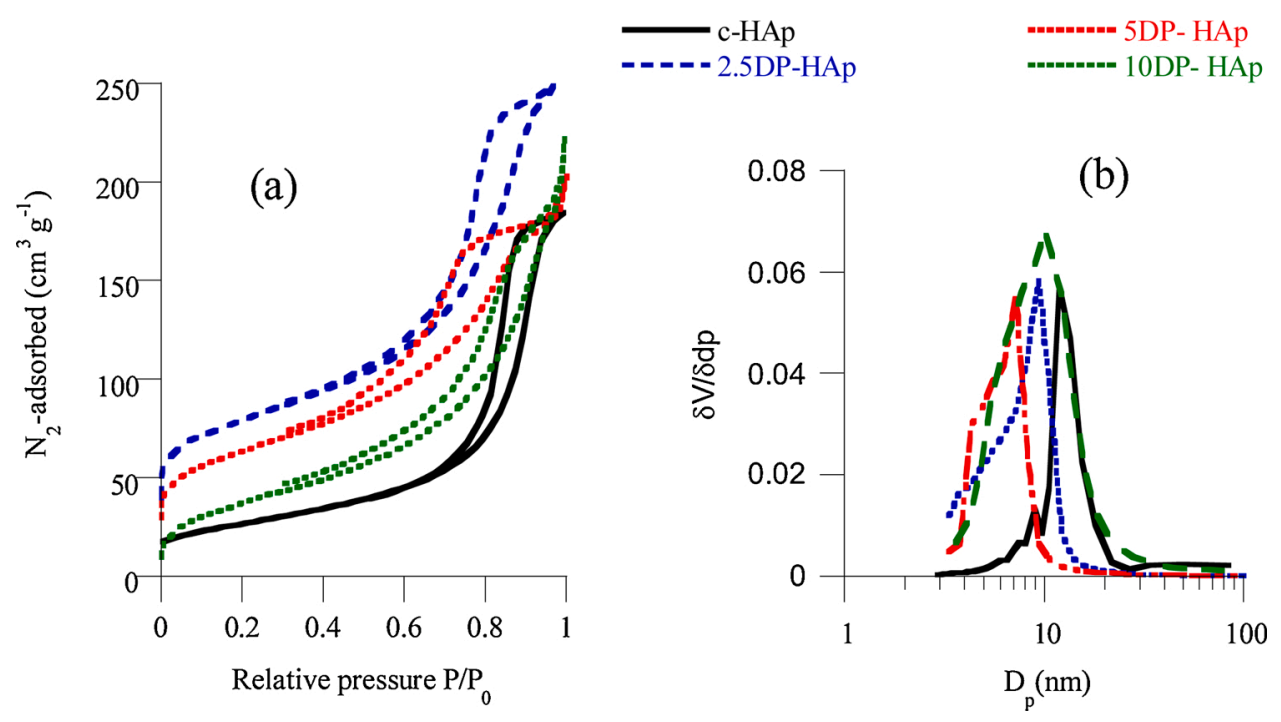

Fig. 5. (a) $\mathrm{N}_{2}$ adsorption-desorption isotherms and (b) Pore size distribution of the studied of the grafted apatites dried at $100{ }^{\circ} \mathrm{C}$.

(a)

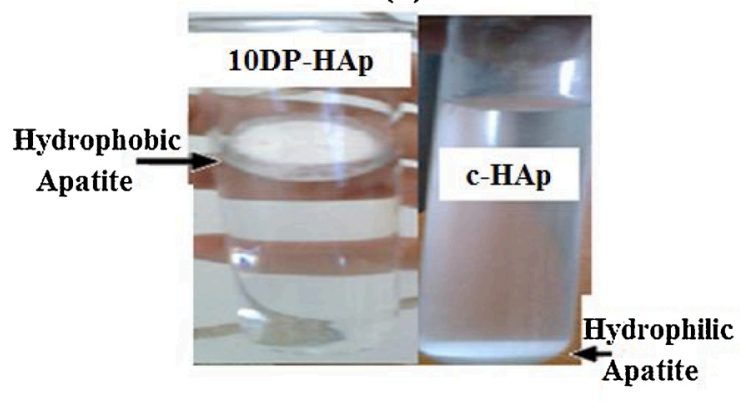

(b)

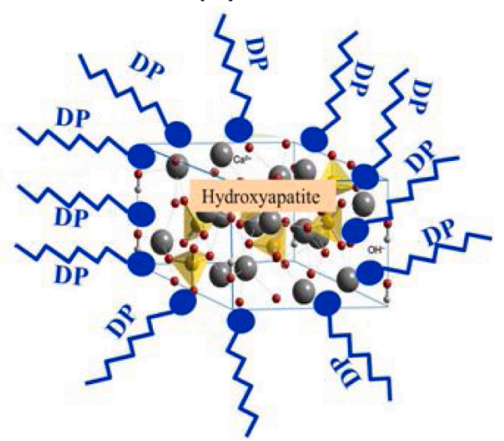

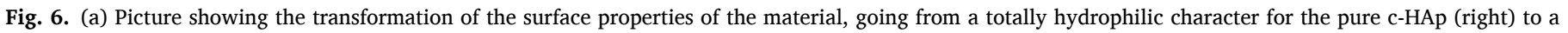

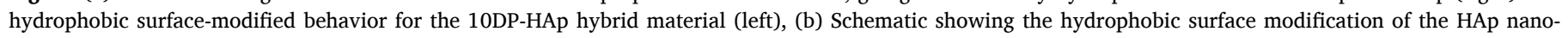
particles with DP coupling agent.

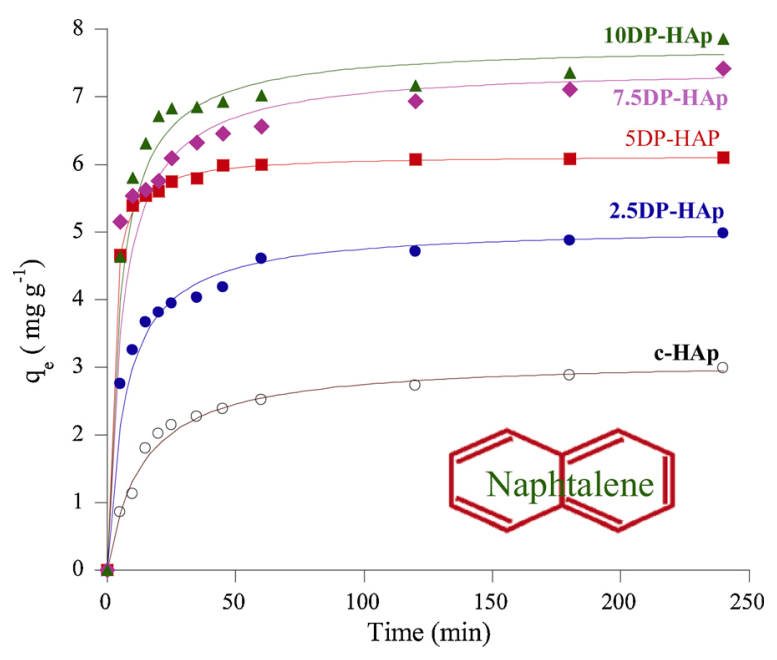

Fig. 7. Kinetics of naphthalene removal $\left(\mathrm{q}_{\mathrm{e}}\right)$ by the hydrophobic apatite nanopowders wDP-HAp compared to the pure c-HAp. Plain lines show the results of data fitting using the pseudo second order Lagergren model.
Table 1

Chemical analyses and surface characteristics of the wDP-HAp materials.

\begin{tabular}{|c|c|c|c|c|c|}
\hline Sample & $\begin{array}{l}\mathrm{Ca} / \\
\mathrm{P}^{\mathrm{a}}\end{array}$ & $\% C^{b}$ & $\begin{array}{l}\text { Weight loss (\%) } \\
200-600{ }^{\circ} \mathrm{C}^{\mathrm{c}}\end{array}$ & $\begin{array}{l}\mathrm{S}_{\mathrm{BET}}\left(\mathrm{m}^{2} /\right. \\
\mathrm{g})^{\mathrm{d}}\end{array}$ & $\mathrm{D}_{\mathrm{p}}(\mathrm{nm})$ \\
\hline NP & 1.95 & 0.38 & 3.6 & 20 & $9.5 ; 13$ \\
\hline C-H Ap & 1.91 & 0.34 & 3.4 & 100 & 12.8 \\
\hline $\begin{array}{l}2.5 \mathrm{DP}- \\
\text { HAp }\end{array}$ & 1.76 & 1.56 & 6.5 & 150 & 9.4 \\
\hline 5DP-HAp & 1.70 & 2.16 & 9.0 & 135 & 8.2 \\
\hline $\begin{array}{c}\text { 7.5DP- } \\
\text { HAp }\end{array}$ & 1.59 & 3.15 & 13.0 & 128 & 10.7 \\
\hline $\begin{array}{l}\text { 10DP- } \\
\text { HAp }\end{array}$ & 1.52 & 4.95 & 17.1 & 110 & 10.7 \\
\hline
\end{tabular}

a From ICP analyses.

b From CHNOS analyses.

c From TG curves.

d BET method. 
Table 2

Kinetic rate constants $\left(\mathrm{k}_{\mathrm{i}}\right)$ and adsorption capacities $\left(\mathrm{q}_{\mathrm{e}, \mathrm{i}}\right)$ as obtained for different models for the naphthalene removal by wDP-HAp powders $\left(\mathrm{C}_{0}=20 \mathrm{mg} \mathrm{L}^{-1}\right.$, dose $=2$ $\left.\mathrm{g} \mathrm{L}^{-1}, \mathrm{pH}=5.6\right) . \mathrm{R}^{2}$ values indicate the correlation coefficients for the linear fits.

\begin{tabular}{|c|c|c|c|c|c|c|c|}
\hline & \multirow[b]{2}{*}{$\begin{array}{l}\mathrm{q}_{\mathrm{e}, \exp } \\
\left(\mathrm{mg} \mathrm{g}^{-1}\right)\end{array}$} & \multicolumn{3}{|c|}{ Pseudo-first-order } & \multicolumn{3}{|c|}{ Pseudo-second-order } \\
\hline & & $\begin{array}{l}\mathrm{k}_{1} \\
\left(\min ^{-1}\right)\end{array}$ & $\begin{array}{l}\mathrm{q}_{\mathrm{e}, 1}\left(\mathrm{mg} \mathrm{g}^{-}\right. \\
\left.{ }^{-}\right)\end{array}$ & $\mathrm{R}^{2}$ & $\begin{array}{l}\mathrm{k}_{2} \\
\left(\min ^{-1}\right)\end{array}$ & $\frac{\mathrm{q}_{\mathrm{e}, 2}(\mathrm{~g} \mathrm{mg}}{\left.{ }_{-1} \mathrm{~min}^{-1}\right)}$ & $\mathrm{R}^{2}$ \\
\hline C-H Ap & 2.84 & 0.026 & 1.99 & 0.9461 & 0.024 & 3.11 & 0.9995 \\
\hline 2.5DP-HAp & 4.86 & 0.024 & 2.10 & 0.9699 & 0.041 & 4.80 & 0.9997 \\
\hline 5DP-HAp & 6.07 & 0.013 & 1.91 & 0.8904 & 0.077 & 6.81 & 0.9999 \\
\hline 7.5DP-HAp & 7.10 & 0.018 & 2.29 & 0.9749 & 0.048 & 7.32 & 0.9994 \\
\hline 10DP-HAp & 7.22 & 0.015 & 1.83 & 0.8418 & 0.050 & 7.77 & 0.9989 \\
\hline
\end{tabular}

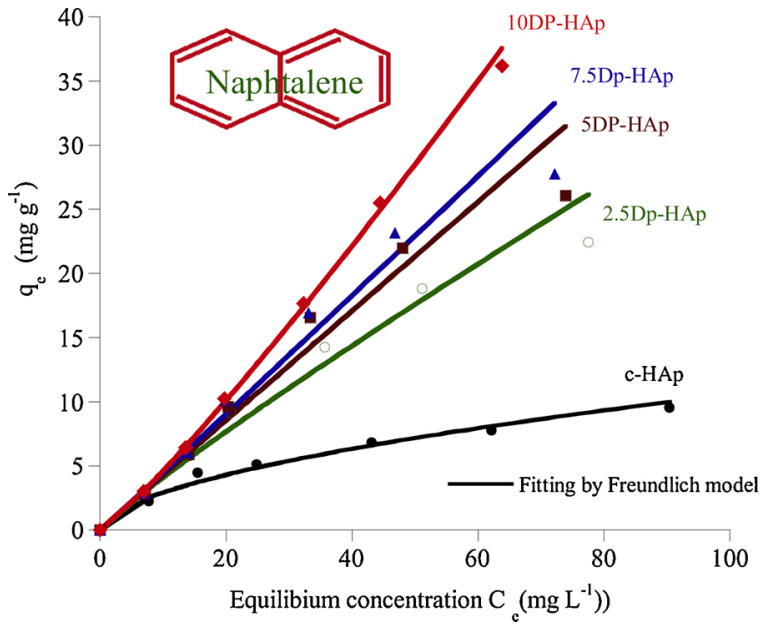

Fig. 8. Effect of initial concentration of naphthalene on its adsorption on the hydrophobic wDP-HAp powders. Lines indicate the result of modeling using the Freundlich equation.

Table 3

Maximum experimental capacity $\left(\mathrm{q}_{\mathrm{e}, \mathrm{exp}}\right.$ ) and constants obtained from the modeling of the naphthalene sorption isotherms using Langmuir and Freundlich equations.

\begin{tabular}{lllllllll}
\hline & \multicolumn{2}{l}{ Langmuir equation } & & \multicolumn{3}{l}{ Freundlich equation } \\
\cline { 2 - 3 } & $\mathrm{q}_{\mathrm{L}}\left(\mathrm{mg} \mathrm{g}^{-1}\right)$ & $\beta\left(\mathrm{L} \mathrm{mg}^{-1}\right)$ & $\mathrm{R}^{2}$ & & & $\log \mathrm{K}_{\mathrm{f}}$ & $1 / \mathrm{n}$ & $\mathrm{R}^{2}$ \\
\hline C-H Ap & 12.9 & 0.027 & 0.9461 & & 0.092 & 0.55 & 0.9789 \\
2.5DP-HAp & 77.0 & 0.005 & 0.9699 & & 0.294 & 0.90 & 0.9896 \\
5DP-HAp & 227 & 0.002 & 0.8904 & & 0.364 & 0.99 & 0.9887 \\
7.5DP-HAp & 400.0 & 0.001 & 0.9749 & & 0.365 & 1.01 & 0.9897 \\
10DP-HAp & 112.3 & 0.004 & 0.8418 & & 0.468 & 1.13 & 0.9995 \\
\hline
\end{tabular}

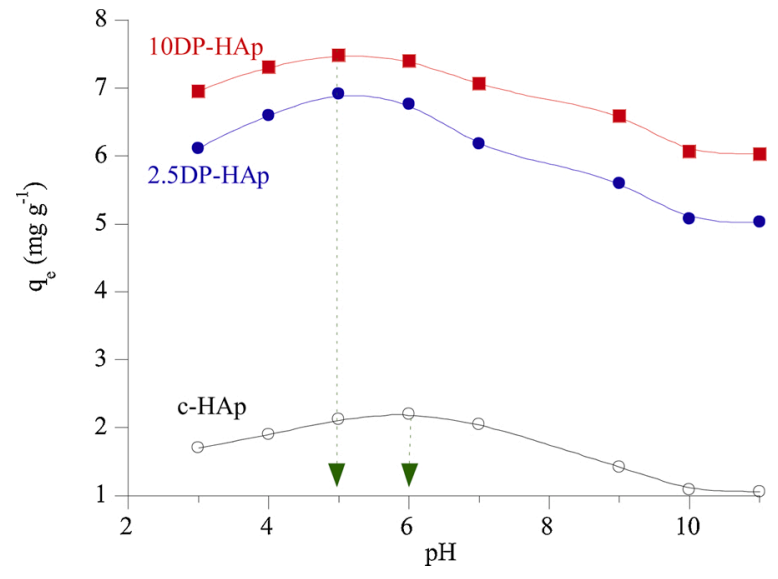

Fig. 9. Effect of initial $\mathrm{pH}$ on the naphthalene removal by c-HAp, 5DP-HAp and 10DP-HAp samples $\left(\mathrm{C}_{0}=20 \mathrm{mg} \mathrm{L}^{-1}, \mathrm{t}=3 \mathrm{~h}\right.$, dose $\left.=2 \mathrm{~g} \mathrm{~L}^{-1}\right)$. Data for 5DP-HAp and 7.5DP-HAp were comparable to 10DP-HAp and are not shown for sake of clarity. 